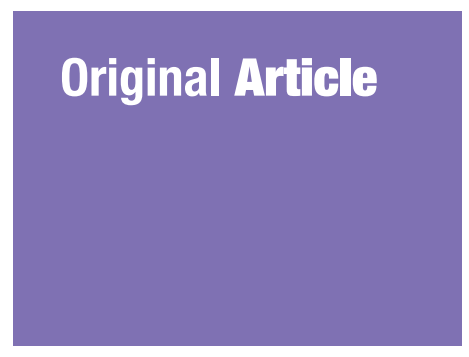

Submitted: 6 Feb 2017

Accepted: 14 May 2019

Online: 30 Apr 2020

\section{The Evaluation of Serum Lipids Profile in Patients with Pemphigus Vulgaris: A Case-Control Study}

\author{
Fahimeh ReZAZAdeH ${ }^{1}$, Maryam MoshaveriniA ${ }^{1}$, Farhad HANDJANI ${ }^{2,3}$, \\ Fatemeh KhoshKнolgh ${ }^{4}$, Nasrin SAKI ${ }^{2,3}$, Alireza HeIRAN ${ }^{5}$ \\ 1 Department of Oral \& Maxillofacial Medicine, School of Dentistry, \\ Shiraz University of Medical Sciences, Shiraz, Iran \\ 2 Molecular Dermatology Research Center, Shiraz University of Medical \\ Sciences, Shiraz, Iran \\ 3 Department of Dermatology, School of Medicine, Shiraz University \\ of Medical Sciences, Shiraz, Iran \\ 4 Dentistry Student, School of Dentistry, Shiraz University of Medical Sciences, \\ Shiraz, Iran \\ 5 Student Research Committee, Shiraz University of Medical Sciences, \\ Shiraz, Iran
}

To cite this article: Rezazadeh F, Moshaverinia M, Handjani F, Khoshkholgh F, Saki N, Heiran A. The evaluation of serum lipids profile in patients with pemphigus vulgaris: a case-control study. Malays $J$ Med Sci. 2020;27(2):57-63. https://doi.org/10.21315/mjms2020.27.2.7

To link to this article: https://doi.org/10.21315/mjms2020.27.2.7

\begin{abstract}
Background: Pemphigus vulgaris (PV) is a chronic autoimmune disease. Dyslipidemia, increased risk of atherosclerosis and higher cardiovascular morbidity, and mortality have been reported in several autoimmune conditions. It has been hypothesised that there might be an association between dyslipidemia and PV. Therefore, the objective of this study was to compare the serum lipid profile of patients with PV with healthy controls.

Methods: This case-control study was carried out on 113 patients with PV and 100 healthy controls. Total cholesterol, high-density lipoprotein (HDL) and triglycerides (TG) levels were measured and low-density lipoprotein (LDL), non-HDL cholesterol (non-HDL-C) and atherogenic index of plasma (AIP) were calculated. Chi-squared test and independent Student $t$-test (or their alternatives) were used for group comparison.

Results: The mean age and BMI of patients and controls were $47.7 \pm 14.5$ and $28 \pm 6.2$ and, $44.5 \pm 18.5$ and $25.5 \pm 5.1$, respectively. Total cholesterol, LDL, HDL, non-HDL-C and TG were statistically different between the two groups $(P$ values $<0.001 ;<0.001 ;<0.001 ;<0.001$ and 0.021 , respectively). However, AIP was not significantly different $(P$-value $=0.752)$.

Conclusion: The serum lipid profile was significantly higher in PV patients compared to healthy controls. Therefore, PV patients may be more prone to develop atherosclerosis and this finding can be important in the overall management of these patients.
\end{abstract}

Keywords: pemphigus vulgaris, cholesterol, triglycerides, serum lipids 


\section{Introduction}

Pemphigus vulgaris (PV), a sub-type of pemphigus, is a bullous skin disease involving the skin and mucosa. This autoimmune blistering disease is characterised by Immunoglobulin $\mathrm{G}$ (IgG) autoantibodies targeted against cell adhesion molecules, desmogleins (DSG) -1 and -3 (1-6). DSG-1 is expressed throughout the epidermis and is highly concentrated in the superficial layers, whereas DSG-3 is expressed in the parabasal and basal layers. In the mucosa, both DSG-1 and DSG-3 are expressed throughout the epidermal layers $(5,7-10)$. In addition, it has been suggested that endoplasmic reticulum (ER) stress is associated with disease pathogenesis (11). The global incidence of PV is approximately 0.076$5 / 100,000$ and women are more prone (1:1.12.25 male to female ratio) $(5,12-13)$. In Iran, the incidence of PV and male to female ratio are 5/100,000 and 1:1.6, respectively (14).

Altered serum lipid levels were investigated in several autoimmune diseases such as rheumatoid arthritis and systemic lupus erythematosus (SLE) (15-16). This suggests that immune response might be associated with atherogenesis, the major cause of cardiovascular diseases (17).

Recently, several studies have proposed the role of increased ER stress and oxidative stress in PV pathogenesis and (or) progression (11, 1819). On the other hand, these two processes are also linked to hyperlipidemia and atherosclerosis (20-21). Hence, theoretically, it appears that there might be an association between dyslipidemia and PV. In this study, we compared the serum lipid profile of patients with PV with healthy controls.

\section{Methods}

In this case-control study, 150 patients with biopsy proven PV using immunofluorescence (IF) and histopathology findings, who were admitted to the dermatology ward of Faghihi Hospital, affiliated with Shiraz University of Medical Sciences from 2012-2015, were enrolled. Exclusion criteria included patients with dyslipidemia, fatty liver, diabetes mellitus, metabolic syndrome, history of stroke, hypertension, cardiovascular diseases, obstructive liver disease, renal diseases, connective tissue diseases, other subtypes of pemphigus, history of smoking and alcohol consumption, family history of dyslipidemia, or the use of drugs interacting with serum lipid measures (cyclosporine, corticosteroids, $\beta$-blockers, thiazides, retinoids, methotrexate and statins, and etc.). Accordingly, 37 patients were excluded based on the above criteria and assessments were done on the remaining 113 patients. One hundred healthy controls, who did not meet the exclusion criteria, were selected through convenience sampling from the emergency ward of the same hospital. Matched case-control methodology was not applied.

The demographic variables (age, gender and body mass index [BMI]) were recorded. After fasting for $14 \mathrm{~h}$, a $5 \mathrm{~mL}$ venous blood sample was taken by a sterile syringe from all participants in the morning and was sent to the hospital laboratory for further analysis. Serum total cholesterol, triglycerides (TG), low-density lipoprotein (LDL) and high-density lipoprotein (HDL) were measured by the enzymatic method using a standard kit (Bionik Diagnostic Systems, Iran). Also, non-HDL cholesterol (non-HDL-C), total cholesterol minus HDL and atherogenic index of plasma (AIP) (log $\left.\left[\mathrm{TG}_{\mathrm{mmol} 1} / \mathrm{HDL}_{\mathrm{mmol} 1}\right]\right)$ were calculated. AIP is a novel metrics in dyslipidemia management, which is a better marker in predicting coronary artery diseases in comparison to single lipid measures such as LDL. We used the Adult Treatment Panel III (ATP III) guidelines from the USA's National Cholesterol Education Programme for normal ranges of the measured parameters.

Rattle GUI (graphical user interface) package powered by $\mathrm{R}$ programming language (version 3.3.1 for Windows) was used for statistical analysis. The univariate analysis was done using Chi-squared test (or Fisher's exact test) or independent Student $t$-test (or Wilcoxon rank-sum test) in order to evaluate the difference between the two groups. $P$-value $<0.05$ was considered to be statistically significant.

\section{Results}

One hundred thirteen cases (50 males and 63 females) were compared with 100 healthy controls (59 males and 41 females). No missing value was in the dataset. The mean age in the case and control group were $47.7 \pm 14.5$ years and $44.5 \pm 18.5$ years, respectively. Both groups were overweight, as the mean BMI was $28 \pm 6.2$ and $25.5 \pm 5.1$ in the case and control group, respectively. Regarding baseline demographic variables, no statistical difference was observed 
for age $(P$ value $=0.093)$, but groups were different according to gender $(P$-value $=0.034)$ and BMI $(P$-value $=0.001)($ Table 1$)$.

Table 2 depicts the case-control lipid profile. In the case group, the mean total cholesterol, LDL, HDL, TG, non-HDL-C and AIP were $190.4 \pm 43.3 \mathrm{mg} / \mathrm{dL}, 115.9 \pm 36.5 \mathrm{mg} /$ $\mathrm{dL}, 46.6 \pm 11.5 \mathrm{mg} / \mathrm{dL}, 135.6 \pm 73 \mathrm{mg} / \mathrm{dL}, 143.8$ $\pm 39.5 \mathrm{mg} / \mathrm{dL}$ and $0.0667 \pm 0.201$, respectively. In the control group, these measures were 155.25 $\pm 37.3 \mathrm{mg} / \mathrm{dL}, 92 \pm 33.3 \mathrm{mg} / \mathrm{dL}, 40.2 \pm 13.1 \mathrm{mg} /$ $\mathrm{dL}, 115.5 \pm 52.7 \mathrm{mg} / \mathrm{dL}, 115 \pm 33 \mathrm{mg} / \mathrm{dL}$ and $0.077 \pm 0.265$, respectively.

The LDL and non HDL-C levels were above the upper limit among the patients. Univariate analysis showed that total cholesterol, LDL, HDL, non-HDL-C and TG were significantly higher in the patient group ( $P$-values < 0.001; $<0.001 ;<0.001 ;<0.001$ and 0.021, respectively). However, AIP was not significantly different between the two groups $(P$-value $=$ 0.752 ).

\section{Discussion}

To our knowledge, Wohl et al. (22) were the first to carry out such a study on the serum lipids profile in PV. In line with our results, they reported that elevated total cholesterol and TG are associated with PV. This finding was confirmed even after controlling for confounding factors. Considering the scarce literature on this subject, only several studies on other skin autoimmune diseases were found. In a study by da Cunha et al. (23), pemphigus foliaceus was linked to a higher serum TG level. Among patients with oral lichen planus, higher Castelli's atherogenic index, TG, total cholesterol and, LDL and lower HDL levels were reported (24, 25). In another study by Taheri et al. (26), patients with psoriasis had a higher plasma lipid profile. In addition, altered serum lipid profile was observed in rheumatoid arthritis, SLE, antiphospholipid syndrome and systemic sclerosis (15-16). Notably, these studies, like ours, were not performed with large sample sizes and BMI, age and gender matched control groups, which could all lead to bias. Change in serum lipid profile in such patients implies that the immune response might be involved in atherogenesis (17). Additionally, the pattern of dyslipidemia differs among various autoimmune diseases, but they all may share the same atherogenic mechanisms (27).

One mechanism that might explain the relationship between dyslipidemia, atherogenesis and autoimmunity is the lipid peroxidation of LDL, which is the key event in the initiation and progression of atherosclerosis. Oxidised low-density lipoprotein (ox-LDL) promotes endothelial dysfunction and pro-inflammatory cytokine release, leading to an autoimmune

Table 1. Demographic characteristics of the patients

\begin{tabular}{lccc} 
& PV $(\boldsymbol{n}=\mathbf{1 1 3})$ & Control $(\boldsymbol{n}=\mathbf{1 0 0})$ & $\boldsymbol{P}^{- \text {value }^{2}}$ \\
Female & $63(55.75 \%)$ & $41(41 \%)$ & 0.034 \\
Age, mean $\pm \mathrm{SD}^{1}$, year & $47.7 \pm 14.5$ & $44.5 \pm 18.5$ & 0.093 \\
BMI, mean $\pm \mathrm{SD}, \mathrm{kg} / \mathrm{m}^{2}$ & $28 \pm 6.2$ & $25.5 \pm 5.1$ & 0.001 \\
\hline
\end{tabular}

Note: ${ }^{1}$ standard deviation; ${ }^{2} P$-value $<0.05=$ statistically significant difference

Table 2. Serum lipids profile in the case and control groups

$\begin{array}{lccc}\text { Lipid or lipoprotein } & \text { PV }(\boldsymbol{n}=\mathbf{1 1 3}) & \text { Control }(\boldsymbol{n}=\mathbf{1 0 0}) & \boldsymbol{P}_{\text {-value }} \text { - }^{1} \\ \text { Total cholesterol, mg/dL }(<200) & 190.4 \pm 43.3 & 155.25 \pm 37.3 & <.001^{2} \\ \text { LDL, mg/dL }(<100) & 115.9 \pm 36.5 & 92 \pm 33.3 & <.001^{2} \\ \text { HDL, mg/dL (40-60) } & 46.6 \pm 11.5 & 40.2 \pm 13.1 & <.001^{2} \\ \text { TG, mg/dL (<150) } & 135.6 \pm 73 & 115.5 \pm 52.7 & 0.021^{3} \\ \text { non-HDL-C, mg/dL (<130) } & 143.8 \pm 39.5 & 115 \pm 33 & <.001^{2} \\ \text { AIP (low risk < 0.1) } & 0.067 \pm .201 & 0.077 \pm .265 & 0.752^{3}\end{array}$

Notes: ${ }^{1} P$-value $<0.05=$ statistically significant difference; ${ }^{2}$ Wilcoxon rank-sum test; ${ }^{3}$ independent Student $t$-test; normal range based on ATP III guidelines 
response that accelerates the intracellular accumulation of lipids within atherosclerotic plaques (28-29) by macrophage scavenger receptors (30). This ox-LDL induces anti-oxLDL-antibody production which is specific for autoimmune disorders (31-33). Also, in both autoimmune and non-autoimmune atherosclerosis, ox-LDL binds to $\beta 2$-glycoprotein I ( $\left.\beta_{2} \mathrm{GPI}\right)$ which forms a circulating complex (ox-LDL/ $\beta 2$ GPI complex). It is likely that $\beta 2 \mathrm{GPI}$ and/or ox-LDL/ $\beta_{2}$ GPI complex contributes to early atherogenesis by stimulating proinflammatory innate immunity through endogenous sensors and inflammasome/ interleukin-1 pathways $(29,34)$.

It is suggested that oxidative stress and ER stress are two pivotal processes in hyperlipidemia and atherosclerosis development $(20-21)$. In addition, recently published studies (11, 18-19) have found the association between these two mechanisms and PV pathogenesis and (or) progression; however, whether increased oxidative stress causes disease manifestations and/or activity or vice versa still remains unknown. The development of ER stress is linked to PV progression (35-36). The protein kinase RNA-like ER kinase (PERK) activates the pro-apoptotic transcription factor that is an enhancer-binding protein homologous protein (CHOP), which induces ER stress-associated cell death (37-39). Furthermore, it is likely that cell exposure to anti-DSG-1 antibodies partially simulates the underlying pathogenic mechanism. The anti-DSG-1 antibodies cause acantholysis, which is the upper layer detachment from the basal membrane, which decreases nutrient supply, homeostasis and normal cell growth, and specifically induces ER stress $(20,40)$.

The present study showed a higher serum LDL level in PV patients. Non-HDL-C is probably the best predictor among all cholesterol measurements both for coronary artery events and strokes (41), and this was also higher among PV patients. Both LDL and non-HDL-C measures were above the normal range. AIP is a marker of lipoprotein particle size, which adds an effective value beyond single lipid measures to predict the risk of atherosclerosis and coronary artery diseases (42-47); however, this marker was not significantly different between PV patients and the control group. One possible explanation might be the fact that the best predictability performance of AIP is when a patient has other cardiovascular risk factors (48).

\section{Conclusion}

In summary, serum lipid profile was statistically different between PV patients and healthy controls; hence, PV patients might be more prone to develop atherosclerosis. Further studies in different populations, with larger sample sizes and considering more variables like severity and duration of the disease, as well as more reliable designs, like cohort studies, are warranted to further validate our findings.

\section{Acknowledgements}

This manuscript is based on the thesis by Fatemeh Khoshkholgh. The authors wish to thank Dr Salehi at the Centre for Research Improvement at the School of Dentistry, for the statistical analysis and $\mathrm{Mr} \mathrm{H}$ Argasi at the Research Consultation Centre (RCC) of Shiraz University of Medical Sciences for his invaluable assistance in editing this manuscript.

\section{Ethics of Study}

This study was approved by the local ethics committee of Shiraz University of Medical Sciences, Shiraz, Iran. All the participants signed the written informed consent form.

\section{Conflict of Interest}

None.

\section{Funds}

The authors thank the Vice-Chancellery of Shiraz University of Medical Sciences for supporting this research project (Grant no. 1834). 
Original Article | Serum lipids in patients with pemphigus vulgaris

\section{Authors' Contributions}

Conception and design: FR, FH, FK, NS

Analysis and interpretation of the data: $\mathrm{MM}$

Drafting of the article: FR, FH, FK, NS

Critical revision of the article for important

intellectual content: FR, FH, MM, FK, NS

Final approval of the article: FH, MM, AH, FK,

NS, FR

Provision of study materials: $\mathrm{AH}$

Obtaining of funding: FR, FH, FK, NS, AH

Administrative, technical, or logistic support: $\mathrm{AH}$

Collection and assembly of data: FR, FK, AH

\section{Correspondence}

Dr Farhad Handjani

Consultant Dermatologist

MD (Shiraz University of Medical Sciences)

Shiraz University of Medical Sciences,

Faghihi Hospital, Zand Avenue,

7134844119 Shiraz, Iran.

Tel: +987132319049

Fax: +98-7132303715

E-mail: hanjanif@yahoo.com

\section{References}

1. Damoiseaux J. Bullous skin diseases: classical types of autoimmune diseases. Scientifica (Cairo). 2013;2013:457982. https://doi.org/10 $.1155 / 2013 / 457982$

2. Sagi L, Baum S, Agmon-Levin N, Sherer Y, Katz BS, Barzilai O, et al. Autoimmune bullous diseases: the spectrum of infectious agent antibodies and review of the literature. Autoimmun Rev. 2011;10(9):527-535. https:// doi.org/10.1016/j.autrev.2011.04.003

3. Schmidt E, Zillikens D. Modern diagnosis of autoimmune blistering skin diseases. Autoimmun Rev. 2010;10(2):84-89. https://doi. org/10.1016/j.autrev.2010.08.007

4. Sticherling M, Erfurt-Berge C. Autoimmune blistering diseases of the skin. Autoimmun Rev. 2012;11(3):226-230. https://doi.org/ 10.1016/j. autrev.2011.05.017

5. Santoro FA, Stoopler ET, Werth VP. Pemphigus. Dent Clin North Am. 2013;57(4):597-610. https://doi.org/10.1016/j.cden.2013.06.002
6. Amagai M, Klaus-Kovtun V, Stanley JR. Autoantibodies against a novel epithelial cadherin in pemphigus vulgaris, a disease of cell adhesion. Cell. 1991;67(5):869-877. https://doi. org/10.1016/o092-8674(91)9036o-b

7. Payne AS, Hanakawa Y, Amagai M, Stanley JR. Desmosomes and disease: pemphigus and bullous impetigo. Curr Opin Cell Biol. 2004;16(5):536543. https://doi.org/10.1016/j.ceb.2004.07.006

8. Amagai M, Koch PJ, Nishikawa T, Stanley JR. Pemphigus vulgaris antigen (desmoglein 3 ) is localized in the lower epidermis, the site of blister formation in patients. $J$ Invest Dermatol. 1996;106(2):351-355. https://doi. org/10.1111/1523-1747

9. Shimizu H, Masunaga $\mathrm{T}$, Ishiko A, Kikuchi A, Hashimoto T, Nishikawa T. Pemphigus vulgaris and pemphigus foliaceus sera show an inversely graded binding pattern to extracellular regions of desmosomes in different layers of human epidermis. J Invest Dermatol. 1995;105(2):153159. https://doi.org/10.1111/1523-1747.ep12316695

10. Ding X, Aoki V, Mascaro JM, LopezSwiderski A, Diaz LA, Fairley JA. Mucosal and mucocutaneous (generalized) pemphigus vulgaris show distinct autoantibody profiles. $J$ Invest Dermatol. 1997;109(4):592-596. https://doi. org/10.1111/1523-1747.ep12337524

11. Mihailidou C, Katsoulas N, Panagiotou E, Farmaki E, Sklavounou A, Kiaris H, et al. Endoplasmic reticulum stress is associated with the pathogenesis of pemphigus vulgaris. Exp Dermatol. 2016;25(9):731-733. https://doi.org/ 10.1111/exd.13026

12. Gupta VK, Kelbel TE, Nguyen D, Melonakos KC, Murrell DF, Xie Y, et al. A globally available internet-based patient survey of pemphigus vulgaris: epidemiology and disease characteristics. Dermatol Clin. 2011;29(3):393404. https://doi.org/10.1016/j.det.2011.03.016

13. Sarig O, Bercovici S, Zoller L, Goldberg I, Indelman $\mathrm{M}$, Nahum $\mathrm{S}$, et al. Populationspecific association between a polymorphic variant in ST18, encoding a pro-apoptotic molecule, and pemphigus vulgaris. $J$ Invest Dermatol. 2012;132(7):1798-1805. https://doi. org/10.1038/jid.2012.46 
14. Asilian A, Yoosefi A, Faghihi G. Pemphigus vulgaris in Iran: epidemiology and clinical profile. Skin Med. 2006;5(2):69-71. https://doi. org/10.1111/j.1540-9740.2006.03756.x

15. Lodde BM, Sankar V, Kok MR, Leakan RA, Tak PP, Pillemer SR. Serum lipid levels in Sjögren's syndrome. Rheumatology (Oxford). 2006;45(4):481-484. https://doi.org/10.1093/ rheumatology/kei19o

16. Missala I, Kassner U, SteinhagenThiessen E. A systematic literature review of the association of lipoprotein (a) and autoimmune diseases and atherosclerosis. Int $J$ Rheumatol. 2012;2012:480784. https://doi. org/10.1155/2012/480784

17. Toms TE, Panoulas VF, Kitas GD. Dyslipidaemia in rheumatological autoimmune diseases. Open Cardiovasc Med. 2011;5:64-75. https://doi. org/10.2174/1874192401105010064

18. Shah AA, Dey-Rao R, Seiffert-Sinha K, Sinha AA. Increased oxidative stress in pemphigus vulgaris is related to disease activity and HLA-association. Autoimmunity. 2016;49(4):248-257. https:// doi.org/10.3109/08916934.2016.1145675

19. Yesilova Y, Ucmak D, Selek S, Dertlioğlu SB, Sula B, Bozkus F, et al. Oxidative stress index may play a key role in patients with pemphigus vulgaris. $J$ Eur Acad Dermatol Venereol. 2013;27(4):465-467. https://doi.org/10.1111/ j.1468-3083.2012.04463.x

20. Ivanova EA, Orekhov AN. The role of endoplasmic reticulum stress and unfolded protein response in atherosclerosis. Int $J$ Mol Sci. 2016;17(2):1-11. https://doi.org/10.3390/ijms150712807

21. Yang RL, Shi YH, Hao G, Li W, Le GW. Increasing oxidative stress with progressive hyperlipidemia in human: relation between malondialdehyde and atherogenic index. $J$ Clin Biochem Nutr. 2008;43(3):154-158. https://doi.org/10.3164/ jcbn.2008044

22. Wohl Y, Dreiher J, Cohen AD. Pemphigus and dyslipidemia: a case-control study. $\mathrm{Br} J$ Dermatol. 2009;161(6):1418-1420. https://doi. org/10.1111/j.1365-2133.2009.09474.x
23. Cunha SF, Santos VM, Monteiro JP, Ferreira TP, Santos JA, Santos TA, et al. Serum lipids of pemphigus foliaceus patients on long-term glucocorticoid therapy. Rev Soc Bras Med Trop. 2003;36(1):1-4. https://doi.org/10.1590/Soo3786822003000100001

24. López-Jornet P, Camacho-Alonso F, RodríguezMartínes MA. Alterations in serum lipid profile patterns in oral lichen planus. Am $J$ Clin Dermatol. 2012;13(6):399-404. https://doi. org/10.2165/11633600-000000000-00000

25. Arias-Santiago S, Buendía-Eisman A, AneirosFernández J, Girón-Prieto MS, GutiérrezSalmerón MT, García-Mellado V, et al. Lipid levels in patients with lichen planus: a casecontrol study. J Eur Acad Dermatol Venereol. 2011;25(12):1398-1401. https://doi.org/10.1111/ j.1468-3083.2011.03983.x

26. Taheri SM, Hedayati MT, Shokohi T, Haj HZ. Serum lipids and lipoproteins in patients with psoriasis. Arch Iran Med. 2014;17(5):343-346. https://doi.org/0141705/AIM.007

27. Sherer Y, Shoenfeld Y. Mechanisms of disease: atherosclerosis in autoimmune diseases. Nat Clin Pract Rheumatol. 2006;2(2):99-106. https:// doi.org/10.1038/ncprheumoog2

28. Mallika V, Goswami B, Rajappa M. Atherosclerosis pathophysiology and the role of novel risk factors: a clinicobiochemical perspective. Angiology. 2007;58(5):513-522 https://doi.org/10.1177/0003319707303443

29. Matsuura E, Atzeni F, Sarzi-Puttini P, Turiel M, Lopez LR, Nurmohamed MT. Is atherosclerosis an autoimmune disease? BMC Med. 2014;12(1):1-5. https://doi.org/10.1186/1741-7015-12-47

30. Haberland ME, Fless GM, Scanu AM, Fogelman AM. Malondialdehyde modification of lipoprotein (a) produces avid uptake by human monocyte-macrophages. $J$ Biol Chem. 1992;267(6):4143-4151. https://doi.org/10.1191/ 096120301680416922

31. Romero FI, Khamashta MA, Hughes GR. Lipoprotein (a) oxidation and autoantibodies: a new path in atherothrombosis. Lupus. 2000;9(3):206-209. https://doi.org/10.1373/ clinchem.2006.073544 
32. Cerinic MM, Valentini G, Sorano GG, D'Angelo S, Cuomo G, Fenu L, et al. Blood coagulation, fibrinolysis, and markers of endothelial dysfunction in systemic sclerosis. Semin Arthritis Rheum. 2003;32(5):285-295. https://doi. org/10.1053/sarh.2002.50011

33. Scanu AM, Fless GM. Lipoprotein (a). Heterogeneity and biological relevance. J Clin Invest. 1990;85(6):1709-1715. https://doi.org/ 10.1172/JCI114625

34. Matsuura E, Lopez LR, Shoenfeld Y, Ames PR. $\beta 2$-glycoprotein I and oxidative inflammation in early atherogenesis: a progression from innate to adaptive immunity? Autoimmun Rev. 2012;12(2):241-249. https://doi.org/10.1016/j. autrev.2012.04.003

35. Spindler V, Waschke J. Desmosomal cadherins and signaling: lessons from autoimmune disease. Cell Commun Adhes. 2014;21(1):77-84. https://doi.org/10.3109/15419061.2013.877000

36. Lanza A, Lanza M, Santoro R, Soro V, Prime SS, Cirillo N. Deregulation of PERK in the autoimmune disease pemphigus vulgaris occurs via IgG-independent mechanisms. Br J Dermatol. 2011;164(2):336-343. https://doi.org/10.1111/ j.1365-2133.2010.10084.x

37. Oyadomari S, Koizumi A, Takeda K, Gotoh T, Akira S, Araki E, et al. Targeted disruption of the Chop gene delays endoplasmic reticulum stress-mediated diabetes. $J$ Clin Invest. 2002;109(4):525-532. https://doi.org/10.1172/ JCI200214550

38. Mihailidou C, Chatzistamou I, Papavassiliou AG, Kiaris H. Regulation of P21 during diabetesassociated stress of the endoplasmic reticulum. Endocr Relat Cancer. 2015;22(2):217-228. https://doi.org/10.1530/ERC-15-0018

39. Mihailidou C, Chatzistamou I, Papavassiliou AG, Kiaris H. Improvement of chemotherapeutic drug efficacy by endoplasmic reticulum stress. Endocr Relat Cancer. 2015;22(2):229-238. https://doi. org/10.1530/ERC-15-0019

40. Stanley JR, Koulu LE, Klaus-Kovtun VE, Steinberg MS. A monoclonal antibody to the desmosomal glycoprotein desmoglein I binds the same polypeptide as human autoantibodies in pemphigus foliaceus. $J$ Immunol. 1986;136(4):1227-1230. https://doi. org/10.1001/archdermatol.2009.224
41. Virani SS. Non-HDL cholesterol as a metric of good quality of care: opportunities and challenges. Tex Heart Inst J. 2011;38(2):160-162.

42. Dobiásová M. AIP--aterogenní index plazmy jako významný prediktor kardiovaskulárního rizika: od výzkumu do praxe [AIP--atherogenic index of plasma as a significant predictor of cardiovascular risk: from research to practice]. Vnitr Lek. 2006;52(1):64-71.

43. Edwards MK, Blaha MJ, Loprinzi PD. Atherogenic index of plasma and triglyceride/high-density lipoprotein cholesterol ratio predict mortality risk better than individual cholesterol risk factors, among an older adult population. Mayo Clin Proc. 2017;92(4):680-681. https://doi.org/10.1016/j. mayocp.2016.12.018

44. Shen S, Lu Y, Qi H, Li F, Shen Z, Wu L, et al. Association between ideal cardiovascular health and the atherogenic index of plasma. Medicine (Baltimore). 2016;95(24):e3866. https://doi. org/10.1097/MD.0000000000003866

45. Zhu XW, Deng FY, Lei SF. Meta-analysis of atherogenic index of plasma and other lipid parameters in relation to risk of type 2 diabetes mellitus. Prim Care Diabetes. 2015;9(1):60-67. https://doi.org/10.1016/j.pcd.2014.03.007

46. Cure E, Icli A, Ugur Uslu A, Baykara RA, Sakiz D, Ozucan M, et al. Atherogenic index of plasma may be strong predictor of subclinical atherosclerosis in patients with Behçet disease. $Z$ Rheumatol. 2017;76(3):259-266. https://doi.org/10.1007/ s00393-016-0141-z

47. Chang Y, Li Y, Guo X, Dai D, Sun Y. The association of ideal cardiovascular health and atherogenic index of plasma in rural population: a cross-sectional study from Northeast China. Int $J$ Environ Res Public Health. 2016;13(10):1-13. https://doi.org/ 10.3390/ijerph13101027

48. Niroumand S, Khajedaluee M, Khadem-Rezaiyan M, Abrishami M, Juya M, Khodaee G, et al. Atherogenic index of plasma (AIP): a marker of cardiovascular disease. Med J Islam Repub Iran. 2015;29:240. 